\title{
Proposed Acquisition and Customer Management Strategy For Titiktemu.Co.Id As An Online Consultation Marketplace Platform In Indonesia
}

\author{
Aisyah Humaerah ${ }^{1}$, Sonny Rustiadi ${ }^{1}$ \\ School of Business and Management, Institute Technology Bandung, Indonesia \\ \{aisyah-humaerah@sbm-itb.ac.id\}
}

\begin{abstract}
Millennials are well-adapted technology users in their daily lives, values, life experiences, motivations, and purchasing behaviour in general (Moreno, Lafuente, Carreom, \& Moreno, 2015). They are shopping for fun, seeking knowledge, freedom, problems breakout, and fantasy embodiment (Babin, Darden, \& Griffin, 1994). As a marketplace for online consultation, the research objective is to analyse customers' characteristics and implementation plan for acquire and manage customers for titiktemu.co.id. Eighteen potential customers are the samples with qualitative methods. This research analyses STP, customer persona, marketing mix, competitor, and USP analysis. Furthermore, it formulated in strategy of customer journey, sales funnelling, and marketing mix. The acquisition strategies are Instagram content, online advertising, website, consultant rules, responsiveness, and collaboration. Furthermore, the retention strategies are formulated for systematic consultation, convenience, group chat, recommendation, and ease of booking and payment. There are consistency service standards and brand recalls for the new revenue and referral strategies.
\end{abstract}

Keywords: Online consultation, customer journey, sales funnelling, marketing mix

\section{Introduction}

Millennials generation is the strong determinant of online shopping behaviour and contributes to the highest percentage of online purchases (Dhanapal, Vashu, \& Subramaniam, 2015). Indonesia millennials who shop online have hedonistic shopping motivation, which means shopping for fun, seeking experience, freedom, problems breakout and fantasy embodiment (Babin, Darden, \& Griffin, 1994). They always develop themselves to anticipate change as a result of technological advances. This is an opportunity for online sellers to increase the online purchase intention of the millennial generation in Indonesia.

Thus, it is suggested to online sellers to: (1) Provide an easily accessible application and the goods/services provided must meet the expectations of the millennial segment. The product should support hedonistic shopping motivation (fun, experience, freedom, problems breakout and fantasy embodiment), the goods must meet the millennial generation product standard, quality, and price. (2) Keep promises and provide commitments such as providing high-quality 
goods and services, meeting the needs and demands of Millennials, and uphold honesty (Salim, Alfansi, Darta, Anggarawati, \& Amin, 2019). Helping the customer or client to solve problem is the consultation's purpose, in which they want to change, achieve, attain or become and which they need help at. They know what their desired state is, but they need an expert's advice or help in getting there (The Definition \& Meaning of A Consultation, n.d.).

The purpose of a consultation is to hear out the millennial's needs and help to identify a plan of attack in solving their problems and accomplishing their goals. So CV HMZ Group has taken the initiative to execute the research on demand for consultations to resolve problems faced by youth in their personal and career lives. The CV HMZ Group company conducted preliminary research on millennial intentions in consultation. This research is internal company research to see the consulting market virtually through video-calls.

This preliminary research uses a random questionnaire distribution method on social media (Twitter, Instagram, and WhatsApp). There are 98 respondents aged 20-35 years. The 20-27year-old category includes Millennial Junior, and the 27-35-years-old category includes Senior Millennial. There were three categories of ages in this research; fifty-eight respondents are 2025 years old. Thirty people aged 26-30 years and nine correspondents $31-35$ years old. The respondents in this survey were 41 women and 56 men. Most of the respondents are college students with $44.9 \%$, employees were $42.86 \%$, and the rest of them were entrepreneurs.

The results show that the desire to consult online is still in the high category, where they want to consult with experienced people, which may be Generation $\mathrm{X}$ is in this category by age. Most millennials are more comfortable consulting in person by online. These factors encourage the company to create a consulting marketplace for millennials through video calls, the website is titiktemu.co.id. The company built the website as a product of intermediary between clients and consultants.

This research will combine the implementation of acquiring and managing customer website in titiktemu.co.id to engage the consultant as supply and the clients as a demand. The Titik Temu website is designed to target the millennial youth category, aged $20-35$ years, which it included in the Junior and Senior millennial category. Initial consulting fields used were business consulting, career, psychology, and finance. The fields selected are based on preliminary research results for consultations that most need solutions for millennials. The consultation media used video-call; this media is chosen as a medium that will create a closer and more intimate relationship between the consultant and the client. This media also uses to minimize the client's time and costs in getting a solution. Based on the business current issue, the researcher defines three research objectives: (1) To analyse the target customers' characteristics of Titik Temu; (2) To find out the best strategy to acquire and manage customers for an online consultation platform; and (3) To design the implementation plan for the proposed strategy.

\section{Literature Review}

This thesis will be focusing on the idea of formulating a strategy to acquire and manage customers for titiktemu.co.id to get more customers. After defining the research's goals or objectives, the researcher has done the first step by reviewing literature or academic papers in marketing. The business analysis examined both internal and external, which are based on secondary data collection. Researchers' secondary data is adjusted to business analysis' needs, starting from customer data, target market, competitor and industry condition.

This research's internal business analysis includes STP (Segmenting, Targeting, and Positioning), customer persona, and marketing mix analysis. The external analysis includes TOWS (Threats, Opportunities, Weaknesses, and Strengths), competitor, and USP (Unique Selling Proposition) analysis. These six analyses support the primary collection and different 
strategy formulation. Primary data collection is done qualitatively through interviews with Titik Temu's target market.

The research base on three main theories: marketing mix, sales funnelling, and customer journey. The formulated strategies will be categorized into three stages based on Steve Blank's sales funnel; (1) get, (2) keep and (3) grow (Blank \& Dorf, 2012). The output of this research is a proposed strategy of acquiring and managing customers for Titik Temu. The strategy defines the implementation plan by applying to Titik Temu launching a new website at the beginning of the business process.

\section{Methodology}

The researcher will survey the competitor users to formulate the strategy of the online consultation platform. Eighteen potential users and three expertise in marketing will be interviewed. Customers' journey, which is a thematic analysis framework, will be used for the next stage to analyse the problem based on the research objectives. The customer journey approach uses to interpret the entire experience of the customer. The researcher will use sales funnelling combined with a marketing mix to analyse marketing activities which is currently being carried out by Titik Temu. Providing insights and solutions for the company to solve problems are the expected outcomes of this analysis.

\section{Findings and Argument}

\section{Customer Journey}

A customer-centric approach should have the company become a lot more demanding in business. This approach aims to maximize customer satisfaction in every phase of customers' journey, from before until after purchase. In addition, this satisfaction influences the customers' loyalty, and it makes a competitive advantage over competitors. Customer journey is a map of a customer's interaction and experience process within particular procedures that are classified into three stages. The preliminary stage, throughout the stage and later, which in the business matter could be described into the pre-purchase, purchase, and post-purchase.



Fig 1. Pre-purchase Stage of Consultation Platform (Formula)

\section{Pre-purchase Stage (Pre-Activation)}

The initial step is pre-purchase-which comprises all aspects of the customer's interaction with the brand, associate, client category, and environment before a purchase transaction. This 
stage could include the customer's complete action before purchase. The conventional marketing research has classified the pre-purchase stage into 'need recognition', 'search', and 'consideration'.

The schema above determines the three formulas of pre-purchase consultation platforms. The first step is need recognition. This initial stage is described in the abbreviation of P-I-S-C$\mathrm{O}$. $\mathrm{P}$ for personal problems, I for ignorance, $\mathrm{S}$ for specific expert, $\mathrm{C}$ for curiosity, and $\mathrm{O}$ for online consultation. The next step is to search. The search step portrays seven points, which are google, LinkedIn, office support, WhatsApp group, Instagram, ask friend and website. This invention is shortened to GLOW IN A SITE. While in the consideration stage, it is determined in AB4CDEFG+2R. This abbreviation means ads, bonus, compatibility, cheaper price, content intensity, clear information, design, expert quality, free consultation, guarantee, recommendation, and responsiveness.

\section{Purchase Stage (Activation)}

The second stage of customer experience covers all customer journeys with the brand and its surroundings during the purchase. This stage includes 'choice', 'ordering', and 'payment'. This stage emphasized how marketing activities, the environment and atmospherics, and the service conditions influence the buying decision. Three touchpoints are consisting within this process, choice, purchase trust, and decision satisfaction. These touchpoints may convince consumers to end seeking and either complete or submit the purchase. The research investigating the purchase stage of the journey should reach inside the digital ecosystems.

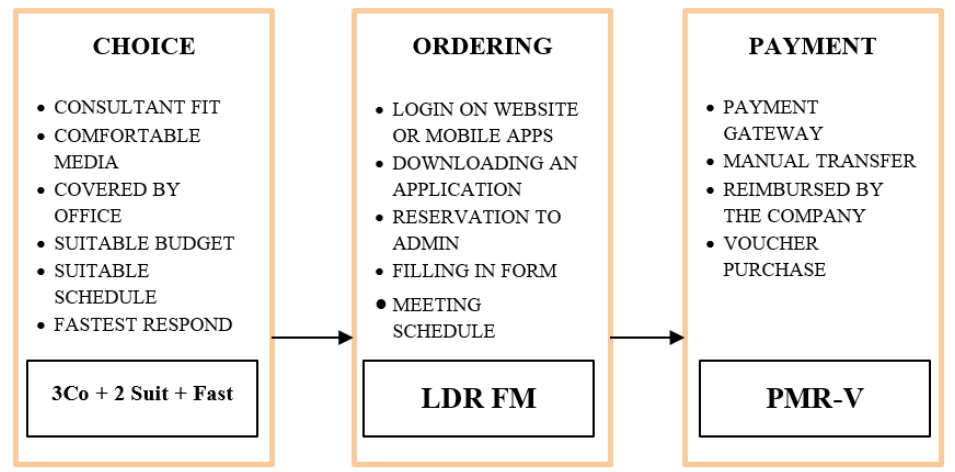

Fig 2. Purchase Stage of Competitor's Customer (Formula)

The chart represents the formula of purchase stage in three steps. There is choice, ordering and payment. Choices emerge in the formula of $3 \mathrm{Co}+2 \mathrm{Suit}+$ Fast. This formula is spelled out for consultant fit, comfortable media, covered by office, suitable budget, suitable schedule, and fastest response. Meanwhile, ordering is described with LDR FM. L for login on website, D for downloading, $\mathrm{R}$ for reservation, $\mathrm{F}$ for filling in form, and $\mathrm{M}$ for meeting schedule. The last step of purchase is payment. Payment process is determined by PMR-V. It is the abbreviation of payment gateway, manual transfer, reimbursed by the company, and voucher purchase.

\section{Post-purchase Stage (Post-Activation)}

The third phase is the post-purchase-contains customer interactions with the brand and its environment following genuine buying. Post-purchase involves 'usage and consumption', 'postpurchase engagement', and 'service requests. Almost similar to the pre-purchase experience, 
this stage could continue temporally from the buying to the end of the customer's journey. Analysis on this part emphasized the consumption reality, service improvement, decisions to exchange products, repurchase or try a variety, and other non-purchase behaviours such as word of mouth and other forms of consumer engagement.

This process includes the loyalty loop as part of the overall customer decision journey. It suggests that a trigger may happen while the post-purchase step leads to customer loyalty through repurchase and further engagement. Also, it started the process recently, with the customer re-entering the pre-purchase phase and considering choices.

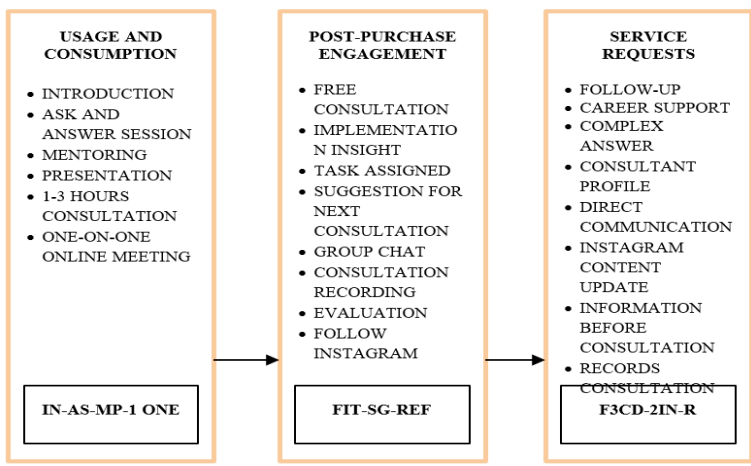

Fig 3. Post-purchase Stage of Competitor's Customer (Formula)

The diagram above shows the formula of post-purchase in consultation platform. This formula is simplified from the usage and consumption, engagement and service request process. The phase of usage described in abbreviations of IN-AS-MP-1 ONE, it means introduction, ask and answer session, mentoring, presentation, 1-3 hours consultation, and one-one online meeting. The next stage of post purchase is conceived by FIT-SG-REF.

This abbreviation means free consultation, insight, task assigned, suggestion for next consultation, group chat, consultation recording, evaluation and follow Instagram. Meanwhile, in the last steps of post purchase is service request. The service request exhibits eight point of respondent's requests, which formulated in F3CD-2IN-R. This formula indicate follow-up, career support, complex answer, consultant profile, direct communication, update content on Instagram, information before consultation, and record consultation

\section{Sales Funneling}

'Get', 'keep' and 'grow' activities are small-scale during the consumer process. It shows the harsh and dirty, or low-loyalty, modest number of customers of a minimum viable product (MVP), to measure the response to the business design (including value proposition, price, and product features). Discovery examines which tactics achieve and gauges first reactions to the MVP.

Sales funnelling strategy focuses on satisfying customers from initial customers then working to keep them, sell to them for a second time, or grow them. Multi-sided marketers need two separated and parallel get approaches - one for the users and another for the buyers, since the value proposition for each is quite different. These marketers need to concentrate on the works on how to reach initial users. A company that has aggregated an audience of many millions can practically indeed find marketers eager to give the privilege of advertising with that audience. 


\section{Customer Acquisition - Get}

Customer acquisition is the phase that compares the awareness, interest, and consideration steps where customers learn and explore a product before they buy it. This phase concentrates on appealing numerous customers to its online front door - the landing page. If there is a high number of people who visit the landing page but do not buy or even try a product, the get plans need to reach many personalities - for a website, that can be millions.

Customer activation is the next stage in the get process, like the purchase step. In activation steps, the consumer exposes interest into a free trial, a request for more information, or a purchase. The company considered activating the customer even if they do not purchase or register, as long as it has enough data to recontact that client (by email, phone, or text).

\section{Customer Retention - Keep}

The goal of the keeping customers is to minimize customer churn/attrition by providing excellent products and services and maintaining a good communication with the customers. At this point, in customer discovery, if there are no customers to retain, the company can identify retention programs to test in the future. Retention program is quickly accessed via online. Firms have incredible potential to trace and control each prospect's, consumer's behaviour, or lack of action (without breaking their privacy).

The result of retention programs is closely monitoring customer behaviour and learning who's staying or leaving. It's crucial to maintain the services, not to track everything but to understand the essential customer behaviours that influence the service to develop. The customer data collection is the key to a retention program that could help personalized the retention effort easily. Trace specific customers' behaviour individually and use that data to create a personal relationship that guides them to the next steps the company wants them to take but always considers personal data privacy.

\section{New Revenue and Referrals - Grow}

There are two techniques to grows existing customers, get the current customers to pay more money, or support them to send more customers to the company. Besides, the company should have a sizeable quantity of customers to grow. The list below is the example of how company may get current customers to spend more and get customer to send more customers.

The researcher lists ten points to making current customers to make purchases again in the consultation business. The lists consist of offering additional services and next consultation to encourage customers to purchase consultation. Most the second consultation will recommend from a consultant or customer service. Customer service gets the customer's data and problem record, this data will push customer service to offer the fit further consultation.

On the other hand, another method to urge customers to pay more consultancy is make chat groups, consistently satisfying customers, provide consultancy packages, hold webinars and make applications. Respondents mention the method for getting new customers from existing customers, there were five points. The lists are referral code, experts' recommendations, consistently maintaining service standard, held promo in Instagram live and fulfil new field consultation.

\section{Strategy Formulation Mind Map}

Figure 4 shows the strategy formulation on Titik Temu platform in the sales funnelling strategy process combined with a marketing mix strategy. Funnelling is divided into three strategies: get, keep, and grow. The three processes, respectively, begin with how Titik Temu, as a marketplace system-based consulting platform, should acquire potential customers to 
become aware, interest, consider and make purchases. All of the below processes represent seven different colours in the marketing mix. Red is for product; orange is for the price factor, yellow is the place, and promotions are coloured green. The blue colour symbolizes the strategy for the people, while the purple colour describes the process in business and pink for physical evidence at the consultation service.

In the awareness stage in acquisition strategy, Titik Temu focuses on promotion by prioritizing Instagram and its online advertising strategy. It means the team should consistently posting content on Instagram by upload videos, pictures, and graphic design. They should comment on another related Instagram account and interact with the followers every day. This strategy suggests reaching more followers to the new customer.

Furthermore, at the interest stage, the team must maintain the consumer process when ordering, making purchases, and after consultation because customers start to get the attraction to communication with the brand. There are four tactics in the interest stage. First is Titik Temu's website. Its strategy combines product, place, and process.

The website of www.titiktemu.co.id is the product, customer can buy the consultant's service in this domain. It is also a place because it facilitates and collects the product catalase in one part. The process starts from the landing page; the customer will read the short description about the product and how to order it. They will click the temukan konsultan page to finding the product they need. Second, the recommendations. Recommendations in the interest stage are representing one of the process steps after talking with friends or professionals.

After talk, they will recommend the consultation. This recommendation will affect the customer to interest to the brand. They will search information and ask the customer service to schedule the consultation. The third strategy is to relate Instagram content to the followers' and customer candidates' problems. These tactics enable the customer to feel a connection between the brand and them. For example, in finance consultancy content, the content may show how to manage monthly expenses.

The fourth context is a fast response. In serving consumers quickly, customer service is needed as people who communicate directly through WhatsApp or Instagram direct messages. In addition, responding is also one of the characteristics that customer service must have in serving consumers. Fast response is made when consumers ask, answer, receive information, and order consulting services. It will appear the interest to the customer candidates.

At the consideration stage, the Titik Temu must pay more attention to the price and promotion factors; the two components dominate when consumers decide on the purchase stage. Furthermore, it is essential to convey the payment process and consultation at the time of purchase to ensure its smooth operation. The easy payment method is the final stage in how Titik Temu reaches consumers. The first strategy is freemium. Freemium was categorized as price tactics, while the consultant agreed to give free consultation in one of the packages offered to the consumer as a trial service. The second tactic is the completeness of consultant data.

This information was required as the consumer's consideration to buy the product because this background consists of consultant's data such as education, work experience, skill, packages price, and schedule. The consultant information was group as product strategy because the main product of Titik Temu is a consultation service by consultants. A match schedule is the fourth strategy. Consideration appears when the consumer and consultant match the meeting schedule. The match schedule is categorized as a product of Titik Temu because the consultancy service provides schedules such as the date and time for meetings. It is also classified as a process strategy because matching the time and date is ordering the consultation services. 
Another tactic is an affordable price. Affordable price is categorized as price and promotion strategy. The packages provided by the consultant on their page showed detailed information about price, service, duration of meeting, and result. Customers will consider the price packages before deciding to purchase. The last tactics in the consideration stage are collaboration and cooperation strategy.

Collaboration refers to the partnership between communities or groups, while cooperation refers to a business-to-business relationship, such as an office consultation service. These strategies will promote the Titik Temu as a consultation platform by giving information to the audience, promo, and social media events. Price will influence the product purchasing in business to the business system because the company buys private consultation for their officers.

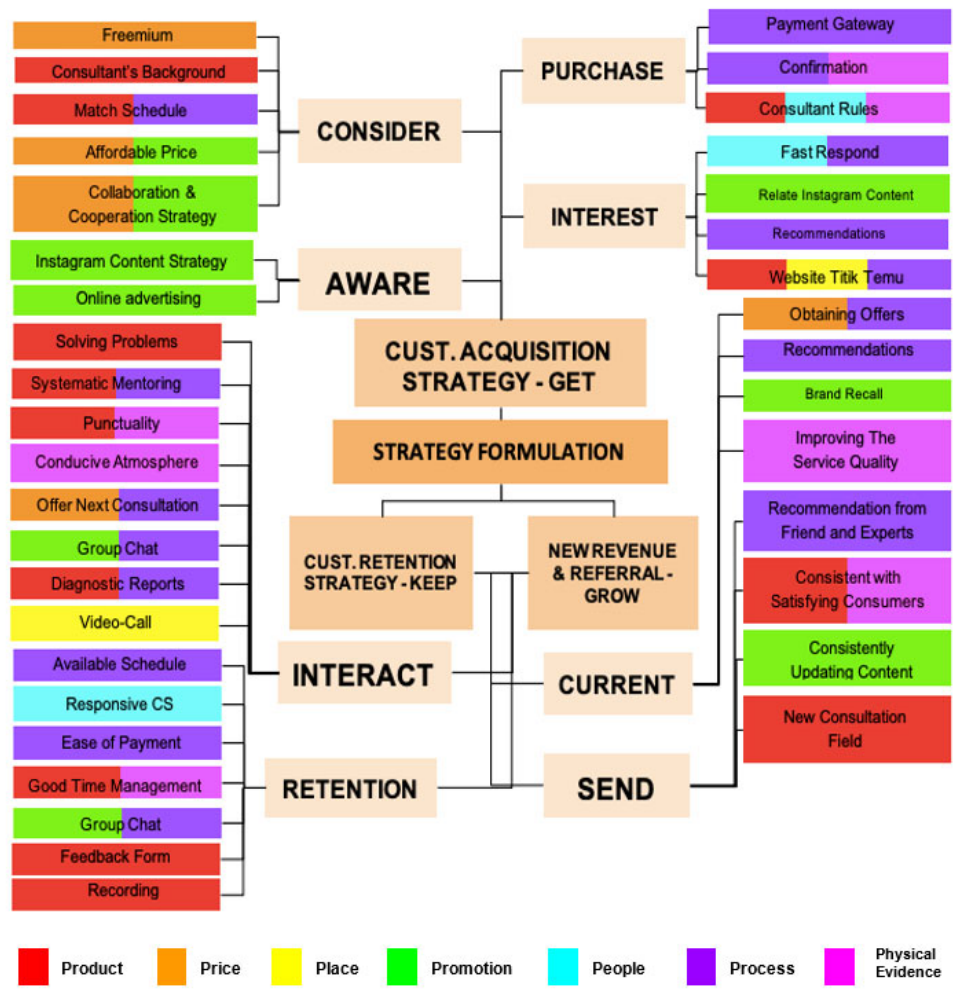

Fig 4. Strategy Formulation Map of Titik Temu

In the purchasing stage, the payment gateway is one of the procedures to ordering the consultation service after the customer chooses the package and filling their data. After payment, the customer will be confirmed by customer service for the ordering by email and WhatsApp. This confirmation is categorized as a process and physical evidence. The last strategy in the purchase stage is consultant rules. These rules involve the consultations as a product, the consultants as people, and physical evidence. The regulations describe the dos and don'ts during the consultation, explained by customer service after payment. 
After getting consumers, the next step is to keep. At this stage, there are two processes, the interaction and retention process. In the interact strategy, the respondents expect the consultation can solve their problem by giving advice, perspective, and solution. This tactic is categorized as a product strategy because it occurs during the consultation. The second strategy is systematic mentoring that relate to the process of consultation. The respondents expect sequential procedures in the consultation session.

Furthermore, another essential aspect is punctuality. Punctuality determines the quality and professionalism of the brand and the experts/consultants. Not only about time, but the conducive atmosphere while consultation influence the convenience in service. The conduciveness is determined by the clear signal, sound, and video. After telling the problem and the consultant gives the response, the consultant will offer the next consultation to the following package or to another expert that can handle the customer problem. The next consultation offering is determined as price and process strategy. The package's price on the consultant's website page is shown in three packages. The customer service of Titik Temu will help the customer to order and paying the services.

For all this procedure, the researcher categorized the offering as the process after problem's solving. The sixth strategy is group chats. This tactic is grouped in the process and promotion strategy. The process of entering consumers into the Telegram group chat is done after the consultation takes place. Customer service will ask for feedback and provide a group chat for clients to ask questions and get new information and knowledge from the consulting field being consulted. It is also part of the promotion in keeping customers to consultation again with Titik Temu platform. The seventh strategy is diagnostic reports. The report is the product of the consultation, the researcher named it Catatan Hasil Konsultasi or consultation result notes. It will clarify the conclusions and recommendations of the talks. The last tactic is the use of video call media. Meeting needs communications, most respondents prefer to use video call because they can see face and expression each other. It builds the communication chemistry between the consultant and clients.

In the retention process, the researcher describes seven tactics. First is the available schedule; the schedule of the retention purchasing will be the essential factor for repurchasing the service. The schedule is categorized as a process because it is the sequence of repurchasing. Responsive customer service is the second strategy included in the people strategy. Responsiveness can be applied when the customer service understands the product knowledge, product value, and promotion goals. The leader should explain the urgency of the service, such as why they should respond quickly. The reason is to make customers not long to wait and satisfy them. Satisfying customers bring sales to the company. The fourth strategy is the ease of payment. The respondents were aware of the payment method; this easiness accelerates the purchasing. So, the payment system is categorized as a process of ordering.

Furthermore, good time management is an essential part of professionalism and the respondents' satisfaction - good time management is marked by punctuality and problemsolving. Product and physical evidence strategy is part of time management. Another tactic is the group chat for the consumer. Like the interact stage, the group chat gives stimulant to the customer by information, promo and answering their questions. It is also categorized as promotion and process. The last strategy is feedback form and recording. Both are mentioned as a product strategy because the feedback result is the services' response from customers and recording as a treatment of giving knowledge that was documented.

Making the new revenue and referral strategy need two methods, from the current customer or send more recent customers. The researcher gets four options to get revenue from the old customer. First strategy is obtaining offers. The old customer that has consult in Titik Temu will 
get offering. This offering will send in email or private messages such as WhatsApp and Instagram direct messages. This proffer is given according to the customer's need from consultation data before. Another strategy to get money is give the recommendations to them.

The recommendations come from the expert or may the customer service as a brand representative. While this way also calls the new consumer too, such as couple consultation or group consultation. Furthermore, the brand recall is the third strategy. Its method will remain the old consumer to remember the assistance of the brand. For example, uploading content in social media every day. The last strategy is consistently improving the service quality. The quality service will improve if the customer service actively asking for a feedback. From that issues, the Titik Temu team can formulate how to make customer more comfortable and satisfy. Consistently satisfying customer can make the current customer invite their friend or family to the platform.

So, it was very essential part to consistently updating content and improving the service. Besides the methods that already explained in get more revenue from current customer, the opening of new consulting field can make more customer because expand market reach.

\section{Conclusions}

The aim of reviewing internal investigation is to answer the first research objective about the target customer's characteristics. The internal analysis examines the segmentation, targeting, and positioning, and a detailed description of the consumer explained in the customer persona. These analyses were analysed and summarized below:

Geographically, the segmentation of Titik Temu takes the millennial market segmentation in seven provincial capitals. The seven cities include Bandung, Surabaya, Semarang, Medan, Banten, Jakarta dan Makassar. In demographic analysis, Titik Temu observes six categories based on the year of birth Indonesia's entire population amounts to around 270.2 million people. In psychographic, research the segmentation pattern and typology between generations in 2019. These studies show Indonesian society divided into three segments psychographic ally-first, the Climbers, the Achievers, and the Socializers.

Meanwhile, behaviourally, Indonesia's consumer behaviour has changed during the new normal covid-19 period experiencing a phase of change. This phase divides into four groups of mega shifts, which explain 30 changes in consumer behaviour. Mega evolutions are a stay-athome lifestyle, the bottom of the pyramid, virtual, and emphatic society. The strategy used in Titik Temu's targeting is differentiated marketing. The consultation has four categories as four different targeting segments. These categories divided the millennials' customers with various backgrounds to consult by the experts. The researcher shaped the product's positioning with four words. These words are your solutive consultation platform. These words are dividing into three components: the core identity, identity structure, and value proportion.

In this position, this clause describes "platform" as a core identity (central of a brand). The "consultation" word means the identity structure that explains what platform is, as an additional word to identify platform words. The two of the first words are "your solutive" as a value proportion of the clause. The term "your" refers to millennials as a target, and it appears they belong to the platform. Solutive means most of the target audience needs to consult because they can solve problems and get solutive knowledge based on professional consultant experience.

The first customer persona shows the figure as a Fahri, an entrepreneur. He has problems in his business, and the problem is about sales and human resources problems. Personal growth 
is a reason for Fahri to fix every problem in his company. To build an excellent sustainable company, he needs someone to accompany him to fix it. To not take the wrong steps, he should ensure that this problem is fixed and guided by the right person. Knowing that the person is capable of sales, he should observe this person's background and then hire him professionally to fix it. Clara is a persona in the second customer persona for Titik Temu.

This person is an active, dedicated and workaholic woman in a metropolitan city. The pressure of life and work environment makes her stressful because she has expectations to achieve her career goals. She does not have many friends because she is not comfortable hanging out with many people. Awarding the mental illness issues that appear in social media and are related to her condition, she compelled to search for a professional to give her guidance or give another insight into her stressing problem. She understands psychologists' jobs professionally and knows a suitable psychologist to solve her problem. So, she should know about the background by looking at consultation websites; this information helps her choose the career expert.

After analyzing the target customer, this research proposes marketing strategies based on competitors' customer experience to find the best approach to acquire and manage customers for an online consultation platform. The method formulates in the sales funnelling plan divided into three processes: acquisition, retention, and new revenue strategy. The acquisition strategy has four stages funnelling: awareness, interest, consideration, and purchase. Besides, the stages of managing customers explain interaction, retention, new revenue from current and new customers. Below is the proposed acquisition and management customers strategy for Titik Temu.

To get the early customer, Titik Temu draws awareness using Instagram contents and online advertisement. Furthermore, at the interest stage, Titik Temu must combine teamwork in maintaining the consumer process when ordering, making purchases, and after consultation. Titik Temu's website is also essential because the website contains three elements: product, place and physical evidence to carry out purchasing. At the consideration stage, the Titik Temu must pay more attention to the price and promotion factors; the two components dominate when consumers begin to decide on the purchase stage. Furthermore, at the time of purchase, it is essential to convey the payment process and consultation to ensure its smooth operation. The easy payment method is the final stage in how Titik Temu reaches consumers.

There are two processes to keep the customers, they are the interaction and retention process. Consumer interactions affect product strategy, the method of communicating with consumers to consultation and after consultation. Titik Temu is also influenced by physical evidence of consultation and media consultation via video-call. At the retention stage, it focuses on product delivery to consumers. The distribution of consulting services to consumers significantly affects retention, how the Titik Temu team provides consulting services according to standards and satisfies consumers.

Besides, the process also involves the stage of the consumer's journey, whether consumers get a responsive response to customer service and continuous service, not only to the client but also to the consultant. The last stage, getting more revenue from existing or new consumers, focuses on consulting services and brand consistency in communicating with the audience. This consistency affects the product, process, promotion, and price strategy.

Implementation plan conducted to make the real action of observation result. This implementation describes the timeline and the action plan to keep in the track on each proposed strategy. The implementation plan has to be started in January 2021, and finish at the end of this year. The timeline made in 12 months as shown below: 
Table 2. Proposed Action Plan of Titik Temu

\begin{tabular}{|c|c|c|c|c|c|c|c|c|c|c|c|c|}
\hline \multirow{2}{*}{\begin{tabular}{|l} 
ACTION PLAN \\
Product
\end{tabular}} & \multicolumn{12}{|c|}{ MONTH } \\
\hline & 1 & 2 & 3 & 4 & 5 & 6 & 7 & 8 & 9 & $\begin{array}{l}1 \\
0\end{array}$ & 11 & 12 \\
\hline \multicolumn{13}{|l|}{ Website Titik Temu } \\
\hline \multicolumn{13}{|l|}{ Consultant Rules } \\
\hline \multicolumn{13}{|l|}{ Consumer Desire } \\
\hline \multicolumn{13}{|l|}{ Price } \\
\hline \multicolumn{13}{|l|}{ Marketplace } \\
\hline \multicolumn{13}{|l|}{ Freemium } \\
\hline \multicolumn{13}{|c|}{ The Good-Better-Best Approach } \\
\hline \multicolumn{13}{|l|}{ Partnership } \\
\hline \multicolumn{13}{|l|}{ Place } \\
\hline \multicolumn{13}{|l|}{ Website Titik Temu } \\
\hline \multicolumn{13}{|l|}{ Media Consultation } \\
\hline \multicolumn{13}{|l|}{ Promotion } \\
\hline \multicolumn{13}{|l|}{ Instagram Content Strategy } \\
\hline \multicolumn{13}{|l|}{ Online Advertising } \\
\hline \multicolumn{13}{|l|}{ Fast and Free Program } \\
\hline \multicolumn{13}{|c|}{ Collaboration and Cooperation } \\
\hline \multicolumn{13}{|l|}{ Group Chat } \\
\hline \multicolumn{13}{|l|}{ Webinars } \\
\hline \multicolumn{13}{|l|}{ People } \\
\hline \multicolumn{13}{|l|}{ Consultant Rules } \\
\hline \multicolumn{13}{|c|}{ The Roles of Customer Service } \\
\hline \multicolumn{13}{|l|}{ Process } \\
\hline \multicolumn{13}{|l|}{ Website Titik Temu } \\
\hline After Consultation Service & & & & & & & & & & & & \\
\hline
\end{tabular}




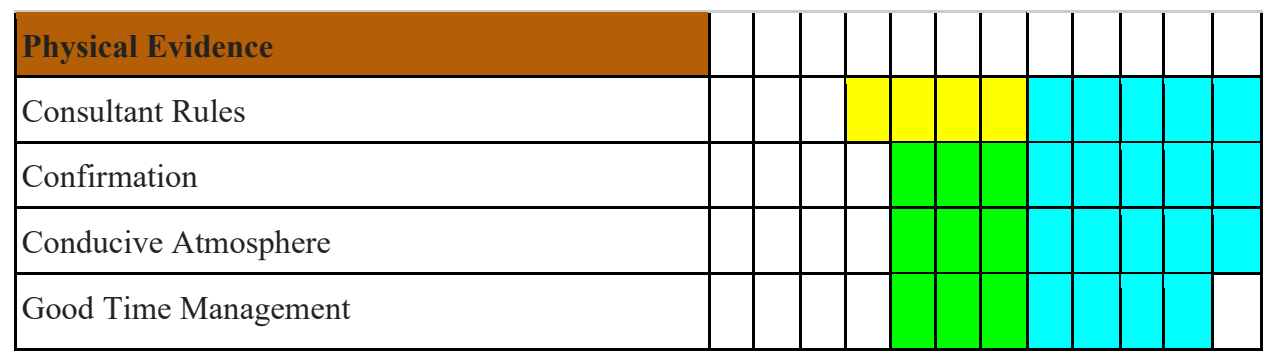

Acquisition Strategy Retention Strategy

New Revenue and Referral Strategy

The table above shows the proposed action plan of Titik Temu based on the sales funneling strategy. This timeline table answers the third research question, designing an implementation proposed in an action plan. The action plan is divided based on the planning for each element of the marketing mix strategy. Each program gives a processing time marked in three different colours. The yellow colour is to implement the initial customer acquisition, followed by a customer retention strategy coloured in green. The method of getting revenue from current and new customers will be coloured blue. All of the above action plans are based on marketing analysis so that their application requires teamwork that is responsible for the product, price, place, promotion, people, process, and physical evidence.

In product strategy, there are websites, consultant rules, and customer desires. Website creation is carried out for five months, starting from the first to the fifth month, while the consultant rules will be after the first consumer begins consultation in the fourth month to the twelfth month. Both of these activities belong to the consumer acquisition strategy. In the consumer desire to get new revenue, the researcher starts the schedule from the fifth month until the end of the year.

The four of pricing strategy is applied from the fourth month except for the partnership strategy that began the implementation on the seventh month; its strategy is used to gain more revenue streams. Marketplace and freemium pricing strategies are categorized as acquisition tactics, while the Good-Better-Best approach is used to get retention from customers.

As a place, media consultation in video communications such as Zoom or Google Meet is categorized as a retention strategy, and its execution began in the fourth month when the first customer comes. The researcher explained promotion in four tricks. Instagram and online advertising strategies are implemented to acquire customers in the sixth month until the end of the year. The free and collaboration program is categorized as an acquisition strategy for four months, but after that, both are classified as retention and new revenue strategy. Another activity is the chatting group. The chatting group starts the enforcement in the fourth month for customer retention. Furthermore, the researcher suggested holding regular webinars in the fifth to eight months.

Besides product strategy, the consultant rules consist of managing people in Titik Temu. The people are the customer, customer service, and consultants. The customer's service is the essential thing that customer was getting value after consultations, so the researcher arranged the specific roles of customer service to control the customer's satisfaction when they accept service. Moreover, the process strategy also manages website procedure, on how the customer will experience getting information or purchasing the consultation service. In comparison, the process after consultation is applied in nine months. 
There are consultant rules, confirmation, a conducive atmosphere, and good time management in the physical evidence strategy. Consultant rules are explained in the product and people strategy. Otherwise, the confirmation from customer service will send when Titik Temu gets the first consumer in the fifth to seventh month as retention for the customer. In contrast, the eight months start to get new revenue by confirming the new offering or product. It is similar to a conducive atmosphere and good time management, both are applied when customer exists, and it will produce more money than for the next consultation.

\section{References}

[1] Babin, B. J., Darden, W. R., \& Griffin, M. (1994). Work and on Fun : Measuring Hedonic and Utilitarian Shopping Value. Journal of Consumer Reserarch Vol 20, 644-651.

[2] Dhanapal, S., Vashu, D., \& Subramaniam, T. (2015). Perceptions on The Challenges of Online Purchasing: A Study from "Baby Boomers", Generation "X" and Generation "Y" Point of Views. Contaduria y Administracion Vol 60 (1), 107-132.

[3] IDN Research Institute. (2019). Indonesia Millennial Report. Jakarta: IDN Research.

[4] Moreno, F. M., Lafuente, J. G., Carreom, A. F., \& Moreno, S. M. (2015). The Characterization of the Millennials and Their Buying Behavior. International Journal of Economic Commerce and Management Vol. 9, 135-144.

[5] Salim, M., Alfansi, L., Darta, E., Anggarawati, S., \& Amin, A. (2019). Indonesia Millennials Online Shopping Behavior. IRMM, -.

[6] I. W. Suastra, Pembelajaran sains terkini. Singaraja: Universitas Pendidikan Ganesha, 2017. 